REVIEW

\title{
Early developmental care for preterm neonates: a call for more research
}

\author{
J Sizun, B Westrup, and the ESF Network Coordination Committee
}

Arch Dis Child Fetal Neonatal Ed 2004;89:F384-F389. doi: 10.1136/adc.2003.025114

Developmental care is the use of a range of medical and nursing interventions to decrease the stress of preterm neonates in neonatal intensive care units. This article reviews the theory underlying such interventions and research based data in different scientific fields, including neuroscience, developmental and family psychology, medicine, and nursing. The conclusion is that more research is needed.

See end of article for authors' affiliations

Correspondence to: Dr Sizun, NICU, Paediatric Department, University Hospital, 29609 Brest, France; jacques.sizun@ chu-brest.fr

Accepted

4 December 2003
$\mathrm{P}$ erinatal mortality has dramatically decreased during the last decade in developed countries as the result of various improvements: in utero transfer, antenatal steroids, surfactant administration, ventilatory support. The survival rates of very low birthweight (VLBW) infants are reported to be $85 \%{ }^{1}$ However, pulmonary morbidity and neurodevelopmental outcome remain two major issues of concern. ${ }^{23}$ Using the 1980 WHO definition of disability, follow up studies of VLBW infants have reported the incidence of disability as 15$25 \% .{ }^{45}$ A recent meta-analysis revealed that, at school age, cognitive scores of former VLBW infants are approximately 10 points lower than those of matched control children ${ }^{5}$ because of difficulties with attention, behaviour, visualmotor integration, and language performance..$^{6-8}$

The following biological factors have been consistently found to be related to mortality and morbidity: gestational age, birth weight, sex, premature rupture of membranes, maternal sepsis, brain white matter injury. The effect of environmental factors on neurodevelopmental outcome has been pointed out. Most studies have focused on family, educational, and economic background but the neonatal intensive care unit (NICU) environment and early practices need more attention than previously granted.

Developmental care is an approach that uses a range of medical and nursing interventions that aim to decrease the stress of preterm neonates in NICUs. ${ }^{9}$ These interventions are designed to allow optimal neurobehavioral development of the infant. A variety of approaches are used: control of environmental stressors known to cause physiological and behavioural disorganisation-for example, light and sound; scheduling of care giving; integration of parents; specific supportive behavioural techniques such as nonnutritive sucking, opportunities for grasping, swaddling and general motor containment; kangaroo care. ${ }^{9}$ Interventions such as these may be integrated into an individualised approach known as the Neonatal individualised developmental care and assessment programme (NIDCAP). ${ }^{10}$

Developmental care has been described as an innovative strategy by some, ${ }^{11}$ but interpreted as useless therapy by others. As with every new intervention, developmental care requires a rigorous scientific evaluation before routine use. This article will review the theoretical framework underlying developmental care interventions and research based data in different scientific fields, including neuroscience, developmental and family psychology, medicine, and nursing.

\section{BRAIN DEVELOPMENT}

At about 24 weeks gestation, neuronal proliferation has just been completed in the ventricular zone of the germinal matrix. Migration of neurones under the guidance of radial glial cells to the cortical layers is in its final stages. Some forms of astrocytes destined for the white matter and the subcortical plate are derived from these radial glial cells, which may have a role in further guiding axonal connections. During this period, myelination begins. Formation and elimination of synapses happen in parallel with selective programmed cell death (apoptosis). In the macaque monkey, as many as 40000 new synapses are formed every second in the visual cortex alone. ${ }^{12}$ It has been calculated that up to $70 \%$ of the neurones in the human cortex undergo apoptosis between the 28th week of gestation and term. ${ }^{13}$

This wiring of neuronal circuits is regulated by endogenous factors ("neurogenetic determinism"), as well as by sensory input and experience ("epigenetic influences"). ${ }^{14}$ In animal models, early abnormal sensory input permanently affects the wiring of neuronal networks and their mode of functioning, as well as neonatal behaviour, if it occurs during the critical period. ${ }^{14}{ }^{15}$ For instance, experiences of pain during the neonatal period have been linked with long lasting accentuated stress responses, ${ }^{16}$ altered neural circuits, ${ }^{17}$ learning deficits, and behavioural changes in rodents. ${ }^{18}$ Chronic suppression of rapid eye movement sleep in the newborn rat results in behavioural changes in the adult and reduced cerebral cortical size. ${ }^{19}$

Abbreviations: NICU, neonatal intensive care unit; NIDCAP, Neonatal individualised developmental care and assessment programme; RCT, randomised controlled trial; VLBW, very low birthweight 


\section{THE HUMAN PRETERM NEONATE}

In the light of these patterns of neural development during critical periods, it could be speculated that development of the human neonatal brain may be negatively influenced by conventional, noxious NICU environments and practices. $^{320-22}$ Sources of stress in the NICU include painful events, medical and nursing procedures, and the physical environment. ${ }^{23}$ One study reported that during a 24 hour observation period, VLBW infants were handled on average more than 200 times. $^{24}$ Three out of four hypoxaemic episodes in preterm infants have been reported to be associated with the care giving itself, ${ }^{25}$ and increased concentrations of stress hormones have been observed in association with routine nursing procedures. ${ }^{26}$

VLBW infants are at high risk of receiving noxious stimulation. Such premature newborns are reported to show hypersensitivity and allodynia, defined as "pain due to a stimulus that does not normally provoke pain". ${ }^{27}$ They also have greater difficulty in maintaining alertness and require more help to regain motor and states stability than full term infants. ${ }^{28} 29$ Preterm infants are also less responsive to interaction than full term infants and show lower levels of behavioural response. As it is more difficult to observe and interpret their signals, parents and care givers may find these children more unpredictable. ${ }^{30}$

The important role of the family in caring for VLBW infants has also been emphasised, ${ }^{31}$ and the concept of family centred care has been strongly advocated. ${ }^{32}$ Minde and collaborators ${ }^{30}$ have shown that neonatal illness may have negative effects on parent-infant interactions. In a study of preterm infants of socially underprivileged mothers, Parker et al ${ }^{33}$ found fewer behavioural problems and better mental development among the children involved in a mother centred developmental care intervention. Optimal school outcome among former preterm children has been shown to be more strongly associated with stability of family composition and level of parental education than with medical complications. ${ }^{34}$

\section{NICU ENVIRONMENT}

The conventional NICU environment has been characterised as having constantly high light and sound levels without day-night differentiation. ${ }^{23}$ The long term impact of NICU environment related sensory input is only beginning to be studied. In its Fifth Consensus Conference on NICU Design (2002) based on clinical experience and updated research findings, the US Committee to Establish Recommended Standards for Newborn ICU Design recommends: ${ }^{35}$

- adjustable ambient lighting levels through a range of 10600 lux;

- separate procedural lighting available at each infant's care station;

- at least one source of daylight with shading devices;

- a combination of continuous background sound and transient sound not exceeding an hourly mean of $50 \mathrm{~dB}$;

- maximum transient sounds not exceeding $70 \mathrm{~dB}$.

\section{DEMONSTRATED IMPACT OF DEVELOPMENTAL CARE}

\section{Non-nutritive sucking}

Non-nutritive sucking has been used during gavage feedings and in the transition from gavage to breast/bottle feeding. The rationale for this intervention is that non-nutritive sucking facilitates the development of sucking behaviour and improves digestion of enteral feeds. A Cochrane metaanalysis including 20 studies, of which 14 had a randomised controlled design, states positive impact on tube to bottle transition, behaviour (improvement of sleep states, decreased stress behaviour during gavage feeding), and length of hospital stay. ${ }^{36}$ The routine use of this easy and inexpensive technique is highly recommended in support of successful feeding.

\section{Massage}

Positive effects of massages have been reported to include increased daily weight gain, improved behavioural development, and shortened hospital stay. Nevertheless, the limited methodological quality of these studies according to the meta-analysis by Vickers et $a l^{37}$ does not permit a definitive conclusion or recommendation for routine use. In very small, fragile infants in particular, massage could have a detrimental effect on autonomic stability.

\section{Kangaroo care}

Kangaroo mother care is defined as skin to skin contact with the baby held close to the mother's chest, frequent and nearly exclusive breast feeding, and early discharge from hospital. This approach has been proposed as an alternative or complement to conventional neonatal care for preterm neonates. A positive effect has been reported, including improved growth and breast feeding rate and reduced nosocomial infections. ${ }^{38}$ However, most trials have been conducted in developing countries, and the results may not have the same relevance in countries where high technology neonatal care is more widely available. ${ }^{39}$

Specific aspects of prevention and treatment of pain Behavioural and environmental strategies for pain prevention and treatment, often referred to as "non-pharmacological treatment", include various developmental care interventions such as non-nutritive sucking, administration of sucrose, swaddling and containment, and limitation of environmental sound and light. ${ }^{40}$ These interventions are recommended by the International Evidence-based Group for Neonatal Pain ${ }^{41}$ as the basis for prevention and treatment of neonatal pain.

\section{NIDCAP}

In the integrated form of developmental care, NIDCAP, the major instrument used is repeated, formalised observations of the infant by someone specifically trained and certified in the method..$^{10}$ These observations focus on the infant's efforts at self regulation, as revealed by approach or avoidance behaviour. When the sensory input is appropriate, the infant will move towards the stimuli and show self regulatory behaviour. In contrast, when the input is overwhelming because the intensity is too great or the timing inappropriate, the infant exhibits avoidance or stress behaviour. Subsequently, care giving plans, including recommendations on individualised care and environmental changes, are designed on the basis of the current developmental stage and medical condition of the infant, as well as the needs of the family. As the infant matures, these recommendations are modified in an appropriate manner.

NIDCAP is family centred. The goal is to support the family by helping them to develop such care skills and techniques, thus including the family as part of the healthcare team. All of the above mentioned individual developmental care strategies, except massage, are often used.

So far, there have been three randomised controlled trials (RCTs) on the effects of full implementation of NIDCAP on VLBW infants. ${ }^{42-44}$ In a meta-analysis, Jacobs and collaborators ${ }^{45}$ report separately on these three RCTs and show a mean difference in length of ventilation of 25.7 days (95\% confidence interval (CI) 7.5 to 43.9) in favour of the intervention. A Cochrane Review ${ }^{9}$ also reported a relative risk for the NIDCAP infants of moderate-severe pulmonary radiographic findings of 0.34 (95\% CI 0.15 to 0.81$)$. In addition, from our own calculations, the relative risk of 
Table 1 Impact of NIDCAP on selected outcome variables

\begin{tabular}{|c|c|c|c|c|c|c|}
\hline & $\begin{array}{l}\text { No of } \\
\text { RCTs }\end{array}$ & Reference & $\begin{array}{l}\text { No of } \\
\text { infants }\end{array}$ & MD & RR & $95 \% \mathrm{Cl}$ \\
\hline \multicolumn{7}{|l|}{ Duration (days) } \\
\hline Ventilation & 2 & $45(42,43)$ & 73 & -27.7 & & -43.9 to -7.5 \\
\hline Supplementary oxygen & 2 & $45(42,44)$ & 59 & -41.1 & & -65.3 to -16.8 \\
\hline Moderate-severe BPD & 2 & $32(42,44)$ & 31 & & 0.34 & 0.15 to 0.81 \\
\hline $\mathrm{IVH} \geqslant$ grade 3 & 3 & $42-44$ & 98 & & 0.51 & 0.23 to 1.10 \\
\hline \multicolumn{7}{|c|}{ Neurodevelopment at 9-12 months } \\
\hline Cognitive & 3 & $45(42-44)$ & 79 & 16.6 & & 9.3 to 23.8 \\
\hline Motor & 3 & $45(42-44)$ & 79 & 9.2 & & 0.7 to 17.8 \\
\hline $\begin{array}{l}\text { Modified from Symington } \\
\text { RCT, Randomised controlle } \\
\text { intraventricular haemorrho }\end{array}$ & and & $\begin{array}{l}\text { obs et al. }{ }^{45} \\
\text { difference; RF } \\
\text { ulmonary dys }\end{array}$ & . & $; \mathrm{Cl}, \mathrm{c}$ & idenc & erval; IVH, \\
\hline
\end{tabular}

intraventricular haemorrhages of grade 3 or more for the NIDCAP infants is 0.51 (95\% CI 0.23 to 1.1 ) (table 1 ).

Jacobs and co-workers ${ }^{45}$ also report a mean difference in the mental developmental index at 9-12 months of age of +16.6 (95\% CI 9.3 to 23.8 ) in favour of the NIDCAP infants. To date, the longest follow up period of a single study is to 2 years of corrected age. ${ }^{46}$ The mental indices in this study were in favour of the NIDCAP group, but the difference was not significant. However, long term development was not the primary outcome in the original design of the study, and one third of the original cohort was lost, which may have introduced sample bias rendering the data somewhat less reliable. A recent report ${ }^{47}$ from a five year follow up of the Swedish RCT showed a significant impact on the NIDCAP group only in the behavioural aspect of development: the odds ratio (OR) for surviving without abnormal behaviour was 19.9 (95\% CI 1.1 to 100$)$. The corresponding OR for survival without mental retardation was 3.5 (0.7 to 100$)$, and for survival without overall disability it was 14.7 (0.8 to 100). No subjects were lost in this follow up, but, for the same reason as in the previous study, the power was very low.

In two NIDCAP RCTs, assessment of neurophysiological functions has been performed with evoked potentials and quantitative topographic mapping of electroencephalograms (brain electrical area mapping, BEAM) ${ }^{42}{ }^{48}$ Both of these studies revealed significant differences in favour of NIDCAP intervention. Interestingly, in the study on the more mature, low risk infants, the largest differences were observed in the frontal lobe area, where neuronal organisation occurs relatively late. ${ }^{48}$ Using quantitative three dimensional magnetic resonance imaging techniques and diffusion tensor imaging at term age, the same investigators recently presented data that indicate beneficial changes in the NIDCAP infants compared with a control group in tissue distributions as well as in microstructural development of the white matter. ${ }^{49}$

In addition, studies on effects of NIDCAP components in specific care giving situations have recently been reported. Sizun and co-workers ${ }^{50}$ showed decreased pain response and fewer hypoxic events during a routine nursing procedure in medically stable preterm infants.

\section{METHODOLOGICAL ISSUES IN DEVELOPMENTAL CARE STUDIES}

Systematic review of research on developmental care is difficult. There are few publications on long term outcome, and many of the published reports are not recent enough and have methodological limitations. ${ }^{95}$

In comparison with drug trials, it is extremely difficult to achieve a standard experimental design in this kind of study. There is no gold standard for nursing care, making the definition of the control group variable; the intervention cannot be applied in a blinded fashion; the experiments may include several individual approaches, which provide confounding factors; and a single procedure may not be analysed separately. Most developmental care studies include small numbers of, generally, healthy preterm newborns, and thus the results are not readily generalisable to infants with acute illness and/or extreme prematurity. The duration of integrated care procedures such as NIDCAP lasts for months, and there is a risk of a spill-over effect on the control group. Parents share experiences with each other and actively seek knowledge designed to improve the treatment of their infant.

\section{RECOMMENDATIONS FOR RESEARCH}

The striking results of developmental care techniques and NIDCAP trials are encouraging, and confirmation by larger, multicentre studies with a multidisciplinary approach is warranted. On the basis of methodological issues, the following key points need to be carefully considered.

- An alternative to randomisation of patients would be randomisation by site, but a large number of sites would be necessary and this would be costly and time consuming.

- Long term neurobehavioral and developmental outcomes need to be chosen as main effects, with blind evaluation and the use of appropriate methods of measurement.

- Short term medical outcomes such as numbers of days on ventilation or oxygen or age at discharge could be unreliable because they are flexible decisions.

- Neurobiological mechanisms could be evaluated using neuroendocrinology, electrophysiology, and functional magnetic resonance imaging.

- These trials should incorporate analysis of cost effectiveness.

- Qualitative research ${ }^{51}$ and continuous quality assessment benchmarking ${ }^{52}$ could be evaluated as an alternative to RCT.

\section{HUMANE ASPECTS}

The dramatic improvement in medical care of infants born prematurely has in many instances led to unintentional conflict between advanced technology and the humane aspects of care. Dr Levin has addressed this problem in his call for a Humane Neonatal Care Initiative, ${ }^{53}$ in which he broadens the concept of the Baby Friendly Hospital Initiative to encompass ill and prematurely born babies. Like Dr Levin, we believe that focusing on respect for the very tiny and often fragile human being and his/her family is not only essential for the further improvement of medical care and developmental outcome, as discussed above, but is also important from a humane point of view.

As pointed out by Kennell, ${ }^{54}$ NIDCAP could be a very effective tool in pursuing the Humane Neonatal Care 
Initiative. The basis of family centred developmentally supportive care is recognition that the newborn infant is a human being in his/her own right, and the encouragement of care givers to be guided by the current needs of the individual infant and its family.

\section{CONCLUSION}

The theoretical framework underlying developmental care interventions is supported by research in several scientific fields, including neuroscience, developmental and family psychology, medicine, and nursing. Current clinical research indicates positive effects of integrated forms of developmental care intervention with a high level of satisfaction to staff. ${ }^{55}$ However, the trials have been relatively few, with small numbers of infants, and the methodology used has been questioned. More research therefore is urgently needed. Trials must be adequate in size, cover diverse cultural contexts, and should use objective measures of child behaviour and development in the long term perspective.

\section{Authors' affiliations}

J Sizun, NICU, Department of Paediatrics, University Hospital, Brest, France

B Westrup, Department of Woman and Child Health, Karolinska Institute, Stockholm, Sweden

Sponsored by the European Science Foundation-European Medical Research Council. JS is supported by the CNP Foundation.

Considerable support came from the European Science Foundation Network Coordination Committee "Research on early developmental care for premature neonates": C Amiel-Tison, Port-Royal, Baudeloque, Paris, France; J V Browne, University of Colorado Health Sciences Center, Denver, CO, USA; M Cuttini, Bambino Gesù Pediatric Hospital, Rome, Italy; G Greisen, Department of Neonatology, Rigshospitalet, Copenhagen, Denmark; D Haumont, Neonatal Unit, St Pierre University Hospital, Brussels, Belgium; P S Hüppi, Unité de Développement, Hôpital des Enfants, Genève, Switzerland; H Lagercrantz, Karolinska Institute, Stockholm, Sweden; K Stjernqvist, Department of Psychology, Lund University, Sweden; I Warren, Winnicott Baby Unit, St Mary's Hospital, London, UK.

\section{REFERENCES}

1 Horbar JD, Badger GJ, Lewit EM, et al. Hospital and patient characteristics associated with variation in 28-day mortality rates for very low birth weight infants. Vermont Oxford Network. Pediatrics 1997;99:149-56.

2 Vaucher YE. Bronchopulmonary dysplasia: an enduring challenge. Pediatr Rev 2002;23:349-58.

3 Bregman J. Developmental outcome in very low birthweight infants. Current status and future trends. Pediatr Clin North Am 1998:45:673-90.

4 Bylund B, Cervin T, Finnstrom O, et al. Morbidity and neurological function of very low birthweight infants from the newborn period to 4 y of age. A prospective study from the south-east region of Sweden. Acta Paediatr 1998;87:758-63.

5 Bhutta AT, Cleves MA, Casey PH, et al. Cognitive and behavioral outcomes of school-aged children who were born preterm: a meta-analysis. JAMA 2002;288:728-37.

6 Hack M, Fanaroff AA. Outcomes of children of extremely low birthweight and gestational age in the 1990's. Early Hum Dev 1999;53:193-218.

7 Stjernqvist K, Svenningsen NW. Ten-year follow-up of children born before 29 gestational weeks: health, cognitive development, behaviour and school achievement. Acta Paediatr 1999;88:557-62.

8 Wolke D, Meyer R. Cognitive status, language attainment, and prereading skills of 6-year-old very preterm children and their peers: the Bavarian Longitudinal Study. Dev Med Child Neurol 1999;4:94-109.

9 Symington A, Pinelli J. Developmental care for promoting development and preventing morbidity in preterm infants (Cochrane Review). Cochrane Database Syst Rev 2003;4:CD001814.

10 Als $H$, Lawhon G, Brown E, et al. Individualized behavioral and environmental care for the very low birth weight preterm infant at high risk for bronchopulmonary dysplasia: neonatal intensive care unit and developmental outcome. Pediatrics 1986;78:1123-32.

11 Wolke D. The preterm responses to the environment: long-term effects? In: Cockburn F, ed. Advances in perinatal medicine. London: Parthenon Publishing Group, 1997:305-14.

12 Bourgeois JP. Synaptogenesis in the neocortex of the newborn: the ultimate frontier for individuation? In: Lagercrantz $\mathrm{H}$, Hanson M, Evrard P, et al, eds. The newborn brain. Cambridge: Cambridge University Press, 2002:91-113.
13 Rabinowicz T, de Courten-Myers GM, Petetot JM, et al. Human cortex development: estimates of neuronal numbers indicate major loss late during gestation. J Neuropathol Exp Neurol 1996;55:320-8.

14 Penn AA, Shatz CJ. Principles of endogenous and sensory activity-dependent brain development. The visual system. In: Lagercrantz $H$, Hanson $M$, Evrard $P$, et al, eds. The newborn brain. Cambridge: Cambridge University Press, 2002:204-25.

15 Lagercrantz H, Ringstedt T. Organization of the neuronal circuits in the central nervous system during development. Acta Paediatr 2001;90:707-15.

16 Liu D, Caldji C, Sharma S, et al. Influence of neonatal rearing conditions on stress-induced adrenocorticotropin responses and norepinepherine release in the hypothalamic paraventricular nucleus. J Neuroendocrinol 2000;12:5-12.

17 Ruda MA, Ling QD, Hohmann AG, et al. Altered nociceptive neuronal circuits after neonatal peripheral inflammation. Science 2000;289:628-31.

18 Anand KJ, Coskun V, Thrivikraman KV, et al. Long-term behavioral effects of repetitive pain in neonatal rat pups. Physiol Behav 1999;66:627-37.

19 Mirmiran M. The importance of fetal/neonatal REM sleep. Eur J Obstet Gynecol Reprod Biol 1986;21:283-91.

20 McCormick MC. The outcomes of very low birth weight infants: are we asking the right questions? Pediatrics 1997;99:869-76.

21 Weindling $\mathbf{M}$. Clinical aspects of brain injury in the preterm infant. In: Lagercrantz $\mathrm{H}$, Hanson $M$, Evrard $P$, et al, eds. The newborn brain. Cambridge: Cambridge University Press, 2002:443-78.

22 Perlman JM. Neurobehavioral deficits in premature graduates of intensive care: potential medical and neonatal environmental risk factors. Pediatrics 2001;108:1339-48.

23 Golson $\mathbf{E}$. The environment of the neonatal intensive care unit. In: Golson $\mathrm{E}$, ed. Nurturing the premature infant: developmental interventions in the neonatal intensive care nursery. New York: Oxford University Press, 1999:3-17.

24 Murdock D. Handling during neonatal intensive care. Arch Dis Child 1984;59:957-61.

25 Long JG, Lucey JF, Philip AG. Noise and hypoxemia in the intensive care nursery. Pediatrics 1980;65:143-5.

26 Lagercrantz H, Nilsson E, Redham I, et al. Plasma catecholamines following nursing procedures in a neonatal ward. Early Hum Dev 1986;14:61-5.

27 Fitzgerald $M$, de Lima J. Hyperalgesia and allodynia in infants. In: Finley GA, McGrath PJ, eds. Acute and procedure pain in infants and children. Progress in pain research and management. Seattle: IASP Press, 2001:1-12.

28 Als H, McAnulty GB. Behavioral differences between preterm and full-term newborns as measured with the APIB system scores: I. Infant Behav Dev 1988; 11:305-18.

29 Eckerman CO, Oehler JM, Medvin MB, et al. Premature newborns as social partners before term age. Infant Behav Dev 1994; 17:55-70.

30 Minde K, Whitelaw A, Brown J, et al. Effect of neonatal complications in premature infants on early parent-infant interactions. Dev Med Child Neurol 1983:25:763-77.

31 Kennell JH. Parent-infant bonding. St Louis, MO: CV Mosby Company, 1982.

32 Saunders RP, Abraham MR, Crosby MJ, et al. Evaluation and development of potentially better practices for improving family-centered care in neonata intensive care units. Pediatrics 2003;111:e437-49.

33 Parker SJ, Zahr LK, Cole JG, et al. Outcome after developmental intervention in the neonatal intensive care unit for mothers of preterm infants with low socio-economic status. J Pediatr 1992;120:780-5.

34 Gross SJ, Mettelman BB, Dye TD, et al. Impact of family structure and stability on academic outcome in preterm children at 10 years of age. J Pediatr $2001 ; 138: 169-75$.

35 Committee to Establish Recommended Standards for Newborn ICU Design. Recommended Standards for Newborn ICU Design (Fifth Consensus Conference on Newborn ICU Design 2002). http://www.nd.edu/ kkolberg/ DesignStandards.htm

36 Pinelli J, Symington A. Non-nutritive sucking for the promotion of physiologic stability and nutrition in preterm infant. Cochrane Database Syst Rev 2001;3:CD001071.

37 Vickers A, Ohlsson A, Lacy JB, et al. Massage for promoting growth and development of preterm and/or low birth-weight infants. Cochrane Database Syst Rev 2000;(2):CD000390.

38 Charpak N, Ruiz-Pelaez JG, Figueroa de CZ, et al. A randomized, controlled trial of kangaroo mother care: results of follow-up at 1 year of corrected age. Pediatrics 2001; 108:1072-9.

39 Conde-Agudelo A, Diaz-Rossello JL, Belizan JM. Kangaroo mother care to reduce morbidity and mortality in low birthweight infants. Cochrane Database Syst Rev 2000;(4):CD002771.

40 Franck LS, Lawhon G. Environmental and behavioral strategies to prevent and manage neonatal pain. In: Anand KJS, Stevens BJ, McGrath PJ, eds. Pain research and clinical management. Amsterdam: Elsevier Science, 2000:203-16.

41 Anand KJS and the International Evidence-Based Group for Neonatal Pain. Consensus statement for the prevention and management of pain in the newborn. Arch Pediatr Adolesc Med 2001; 155:173-80.

42 Als H, Lawhon G, Duffy FH, et al. Individualized developmental care for the very low-birth-weight preterm infant. Medical and neurofunctional effects. JAMA 1994;272:853-8.

43 Fleisher BE, VandenBerg K, Constantinou J, et al. Individualized developmental care for very low birthweight premature infants improves medical and neurodevelopmental outcome in the neonatal intensive care unit. Clin Pediatr 1995;34:523-9.

44 Westrup B, Kleberg A, von Eichwald K, et al. A randomized controlled trial to evaluate the effects of NIDCAP (Newborn Individualized Developmental Care and Assessment Program) in a Swedish setting. Pediatrics 2000;105:66-72. 
45 Jacobs SE, Sokol J, Ohlsson A. The Newborn Individualized Developmental Care and Assessment Program is not supported by meta-analyses of the data. J Pediatr 2002;140:699-706.

46 Ariagno RL. Developmental care does not alter sleep and development in premature infants. Pediatrics 1997; 100:E9.

47 Westrup B, Böhm B, Lagercrantz H, et al. Preschool outcome in children born very prematurely and cared for according to the Newborn Individualized Developmental Care and Assessment Program (NIDCAP). Acta Paediatr 2004:93:498-507.

48 Buehler DM, Als H, Duffy FH, et al. Effectiveness of individualized developmental care for low-risk preterm infants: behavioral and electrophysiologic evidence. Pediatrics 1995;96:923-32.

49 Als H, Duffy FH, McAnulty G, et al. Early experience alters brain function and structure. Pediatrics 2004;113:846-57.
50 Sizun J, Ansquer H, Browne J, et al. Developmental care decreases physiologic and behavioral pain expression in preterm neonates. J Pain 2002;3:446-50.

51 Barbour RS, Barbour M. Evaluating and synthesizing qualitative research: the need to develop a distinctive approach. J Eval Clin Pract 2003:9:179-86.

52 Carteaux P, Cohen $\mathrm{H}$, Check J, et al. Evaluation and development of potentially better practices for the prevention of brain hemorrhage and ischemic brain injury in very low birth weight infants. Pediatrics 2003:111:e489-96.

53 Levin A. Humane Neonatal Care Initiative. Acta Paediatr 1999;88:353-5.

54 Kennell JH. The Humane Neonatal Care Initiative. Acta Paediatr 1999;88:367-70.

55 Westrup B, Stjernqvist K, Kleberg A, et al. Neonatal individualized care in practice: a Swedish experience. Semin Neonatol 2002;7:447-57.

\section{IMAGES IN NEONATAL MEDICINE}

\section{Neonatal acute gastric volvulus}

\begin{abstract}
5 day old baby boy with persistent bilious vomiting was referred to our neonatal unit. He passed normal stools and his abdomen was soft and non-tender. A plain radiograph of the chest and abdomen (fig 1) showed that the dome of the left diaphragm was elevated, suggesting eventration. The oesophagus was dilated, a gastric air shadow could be seen in the left chest, and there was no gas shadow in the abdomen. An upper gastrointestinal contrast study (fig 2) revealed left sided diaphragmatic eventration and organoaxial gastric volvulus. Laparotomy revealed an eventrated left hemidiaphragm with a distended, volvulated stomach.

Acute gastric volvulus is a rare cause of persistent vomiting in infancy or childhood and is due to an abnormal rotation of one part of the stomach around another. There are two main anatomical forms of gastric volvulus. ${ }^{1}$ In the more common, organoaxial volvulus, the stomach rotates around an axis connecting the cardia and the pylorus, and in the less common, mesenteroaxial volvulus, the stomach rotates around a transverse axis connecting the middle of the greater and lesser curvatures (fig 3). In an infant with unexplained vomiting, gastric volvulus should always be suspected on a plain abdominal radiograph, when associated with a left diaphragm anomaly. ${ }^{2}$
\end{abstract}

\section{ACKNOWLEDGEMENTS}

Thanks to Ashwin Prakash for the schematic representation in fig 3.

P Manikoth, P A K Nair Special Care Baby Unit, Department of Child Health, Royal Hospital, Muscat, Oman; manikoth@omantel.net.om N Zachariah, M J Sajwani Department of Paediatric Surgery, Royal Hospital, Muscat, Oman

\section{REFERENCES}

1 Tam PKH. Stomach and gastric outlet. In: Neill VF, David MB, Mervyn GE, eds. Surgery of the newborn, 1st ed. London: Churchill Livingstone, 1994:86-7.

2 Cameron AEP, Howard ER. Gastric volvulus in childhood. J Pediatr Surg 1987;22:944-7.

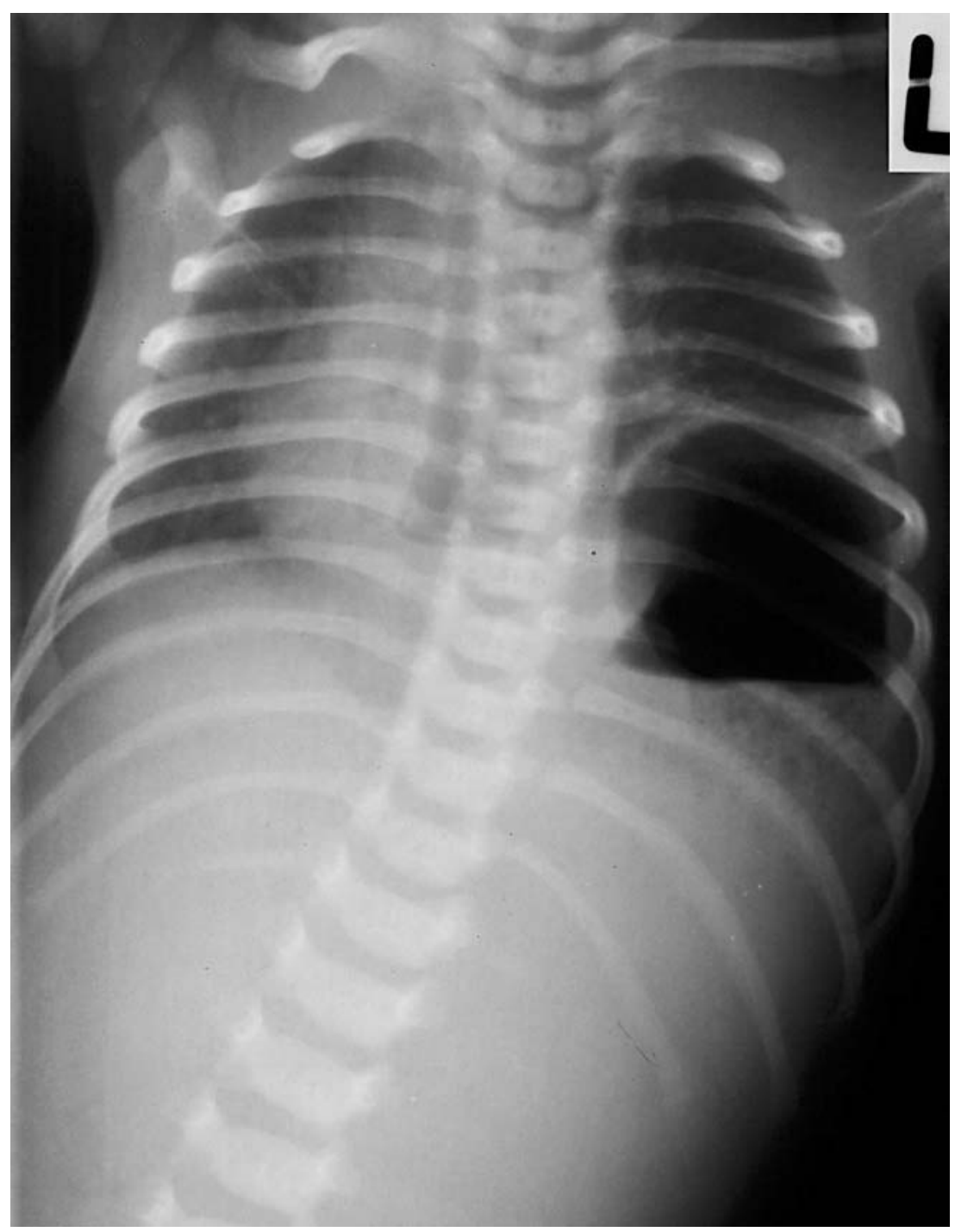

Figure 1 Plain radiograph of chest and abdomen showing left diaphragmatic eventration with gastric air shadow in left chest, dilated oesophagus, and gasless abdomen. 


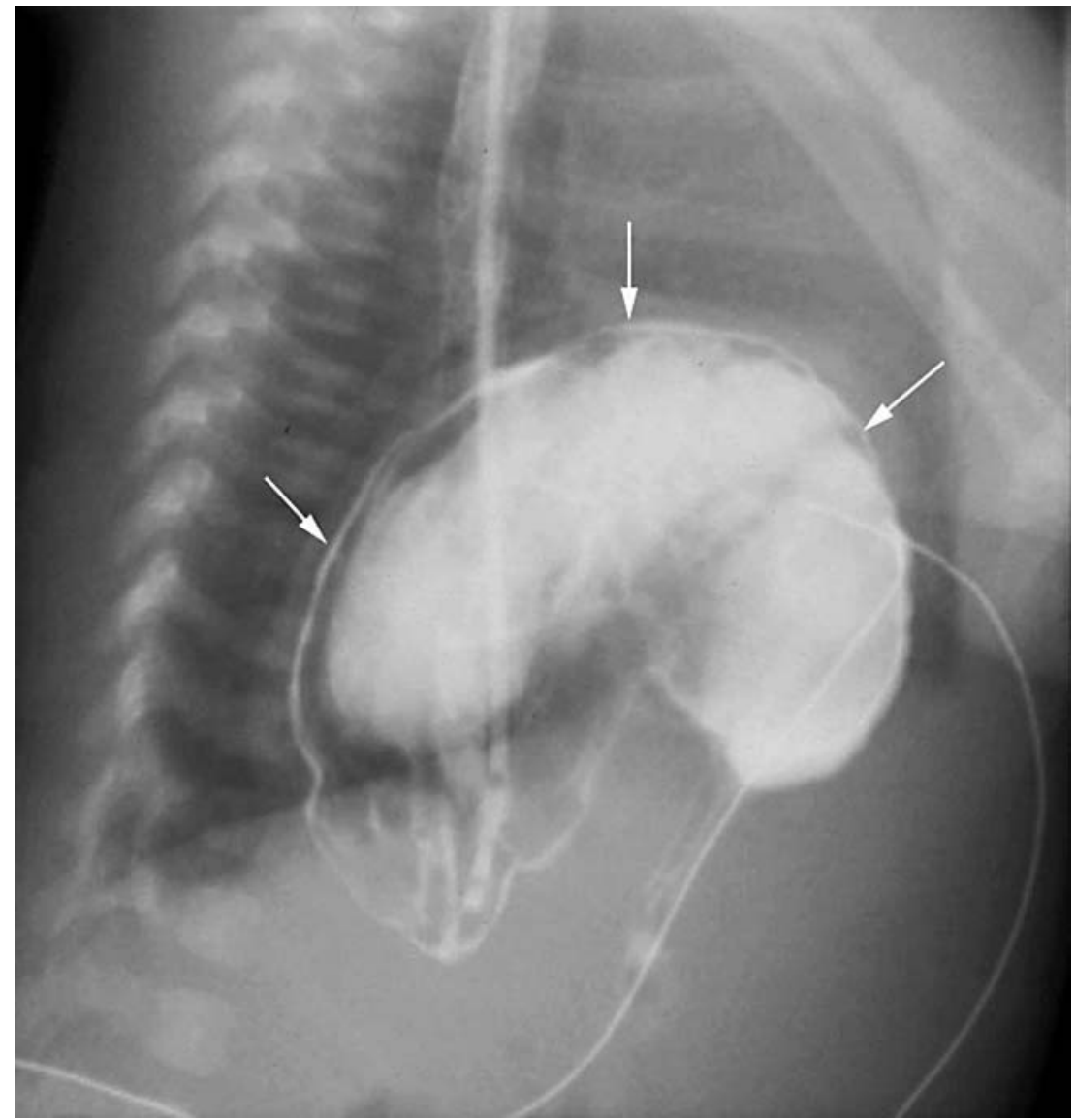

Figure 2 Upper gastrointestinal contrast study lateral view showing left diaphragmatic eventration and organoaxial gastric volvulus: upside down stomach with reversal of greater and lesser curvatures, greater curvature (white arrows) crossing the oesophagus, and gastric outlet obstruction.

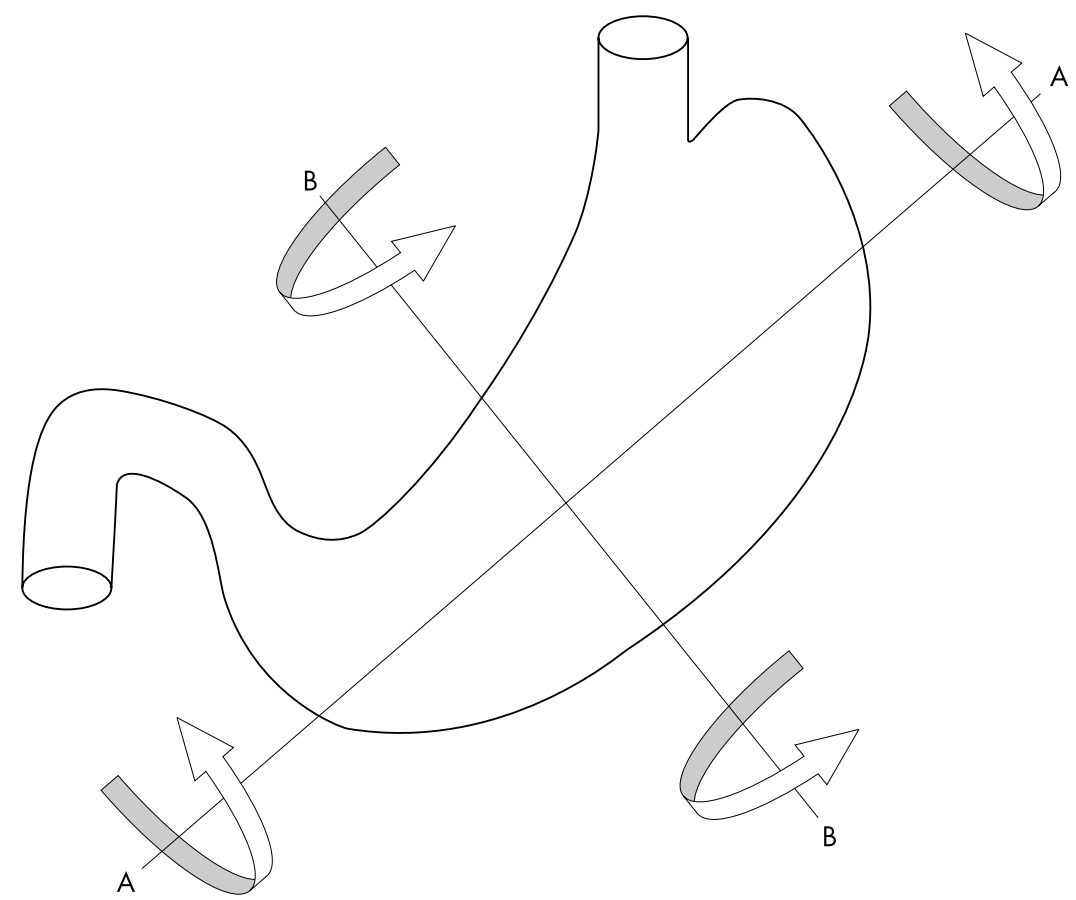

Figure 3 Schematic representation of the two types of gastric volvulus: organoaxial volvulus occurs around the line A-A and mesenteroaxial volvulus occurs around the line B-B. 